\title{
EDUCAÇÃO DE JOVENS E ADULTOS E HOMOAFETIVIDADE: RELATO DAS CONCEPÇÕES DOS ALUNOS E DEBATE ACERCA DO TEMA
}

\author{
YOUTH AND ADULT EDUCATION AND HOMOAFECTIVITY: REPORT OF \\ STUDENTS 'CONCEPTIONS AND DEBATE ABOUT THE THEME
}

\author{
Tito Marcos Domingues dos Santos
}

${ }^{1}$ Universidade Estadual do Rio de Janeiro, Departamento de Educação, Brasil, email:titodomingues1@hotmail.com

\author{
ARTICLE INFO \\ Article history: \\ Received 2020-02-23 \\ Accepted 2020-02-20 \\ Available online $2020-06-20$
}

\begin{abstract}
Palavras-chave: Educação de jovens e adultos. Homoafectivity. Diálogo.

Keywords: Youth and adult education. Homosexuality. Dialogue.
\end{abstract}

RESUMO. Um professor de Geografia da Rede Estadual (RJ), introduziu o conteúdo relacionado aos movimentos sociais que incluiu importantes lutas, como da etnia afro-brasileira, da comunidade LGBT, do movimento sem-terra, do movimento passe livre e outros. Solicitou que sua turma da EJA se organizasse em grupos para que os mesmos optassem em pesquisar e apresentar um dos movimentos. Observou-se que ao final das escolhas dos temas, nenhum grupo havia demonstrado interesse em apresentar o movimento LGBT. Esse trabalho objetiva narrar e problematizar a interferência pedagógica do professor, após propor um diálogo com seus alunos acerca da homoafetividade, ao ressaltar o espaço de sala de aula enquanto lócus favorável à reflexão e ao combate a toda expressão de preconceito. Utilizou-se como aparato teórico-metodológico os estudos de Louro. Após o tema ser discutido, os (as)alunos (as) passaram a apresentar discurso favorável à diversidade de gênero. A intervenção proposta pelo professor mostrou que suas concepções negativas acerca da homoafetividade eram resultantes da falta de informação, estudo e diálogo acerca do tema.

\begin{abstract}
A Geography teacher from the State Network (RJ), introduced content related to social movements that included important struggles, such as Afro-Brazilian ethnicity, the LGBT community, the landless movement, the free pass movement and others. He asked his EJA class to organize themselves in groups so that they would choose to research and present one of the movements. It was observed that at the end of the choice of themes, no group had shown interest in presenting the LGBT movement. This work aims to narrate and problematize the pedagogical interference of the teacher, after proposing a dialogue with his students about homo-affectivity, emphasizing the classroom space as a favorable place for reflection and combating any expression of prejudice. Louro's studies were used as a theoretical and methodological apparatus. After the topic was discussed, the students began to present a discourse favorable to gender diversity. The intervention proposed by the teacher showed that his negative conceptions about homoafectivity were the result of a lack of information, study and dialogue on the topic.
\end{abstract}




\section{Introdução}

No Colégio Estadual Marlucy Salles de Almeida, na Cidade de São Gonçalo -RJ, um professor da Disciplina de Geografia resolveu propor o conteúdo, movimentos sociais, em sua turma do módulo III da Nova Educação de Jovens e Adultos. Tratava-se de uma turma composta por 34 alunos (as) entre 18 a 53 anos de idade.

Sugeriu que a turma se dividisse em grupo e escolhesse um dos movimentos propostos: movimento negro, movimento passe livre, movimento sem-terra, movimento sem teto e movimento LGBT (Lésbicas, Gays, Bissexuais e Transexuais). A proposta tinha como objetivo levar os alunos a conhecer os ideais de luta e conquistas históricas de cada movimento selecionado.

Após a escolha dos temas, constatou-se que nenhum dos grupos haviam manifestado interesse em pesquisar o movimento LGBT.

É importante frisar que mais de um grupo tenha demonstrado interesse em pesquisar e apresentar um mesmo movimento social. Por exemplo, dois grupos optaram em apresentar o movimento negro e dois grupos demonstraram interesse em apresentar o movimento passe livre. Porém, o movimento LGBT não foi escolhido por nenhum dos grupos da turma.

O professor da Disciplina de Geografia, a priori, não interferiu nas escolhas dos alunos, pois sua proposta visava à escolha de um movimento que mais trouxesse interesse e identificação. Porém, após a apresentação dos trabalhos pelos grupos de alunos, foi possível abrir uma proposta de diálogo, onde seria averiguado as concepções da turma acerca do movimento LGBT e da homoafetividade.

Este relato de experiência visa descrever a intervenção pedagógica do professor da Disciplina de Geografia diante da temática da homossexualidade, através do diálogo com seus (suas) alunos, após identificar uma certa aversão da turma em relação ao movimento LGBT.

Essa intervenção dialógica ocorreu no mês de junho do ano de 2016.

É importante salientar que todos os alunos da turma autorizaram a divulgação e a publicação desse trabalho.

Nas linhas que se seguem, será desenvolvido o relato de experiência, problematizando-o com os estudos de Louro (2003). 


\section{Desenvolvimento}

A proposta de diálogo surgiu no momento em que o professor da Disciplina de Geografia percebeu que muitos alunos da turma, apesar de não ter demonstrado preconceito acerca do movimento LGBT, estavam tímidos em optar pela temática. Provavelmente, estavam mais preocupados com a reação dos colegas, pois se tratava de pesquisar e apresentar os objetivos e as conquistas de um movimento que luta pela causa onde estão embutidas várias representações, concepções sociais acerca de gênero e que se destoam dos tradicionais valores difundidos pela igreja, família e Estado tradicional.

É relevante salientar que entre os alunos da turma, alguns se declaravam católicos, outros se declaravam evangélicos e, ainda outros, se declaravam espíritas e/ou de religiões de matrizes africanas.

Reconhecer essa diversidade religiosa, foi crucial para que o professor fosse cauteloso em suas perguntas, para não ferir a fé religiosa de muitos alunos que estavam inseridos naquele grande grupo diverso.

Foi necessário introduzir um diálogo onde o professor não demonstrasse maniqueísmo das ideias, ou seja, o princípio de que o bem e o mal pertencem a dois polos divergentes e que não se inter-relacionam. Optou-se pelo diálogo, onde a dialética pudesse direcionar as discussões. Não se poderia desvalorizar as concepções dos alunos católicos e evangélicos que se opusessem aos ideais do movimento, nem, tampouco, superestimar as concepções daqueles que se posicionassem simpatizantes do movimento e que não demonstrassem preconceito de gênero.

O fato de nenhum grupo ter escolhido pesquisar e apresentar o movimento LGBT, não foi apontado e nem criticado pelo professor. Porém, sua intervenção dialógica poderia levar a turma a se questionar, por si própria, acerca dos motivos da rejeição e, também, construir novas concepções acerca do movimento LGBT e da homossexualidade. A intervenção se fazia necessária, pois, o professor não poderia deixar de defender sua ideia de que, no âmbito dos movimentos sociais, o movimento LGBT possui sua credibilidade e é digno de ser estudado e respeitado como qualquer outro movimento. Mas, era inadequado culpar os alunos por suas concepções contrárias e até mesmo indiferentes ao movimento. Antes, segundo Louro (2003, p.83):

Para que possamos pensar em qualquer estratégia de intervenção é necessário, sem dúvida, reconhecer as formas de instituição das desigualdades sociais. A sensibilidade e a disposição para se lançar a tal tarefa são indispensáveis, mas as teorizações, as pesquisas e os ensaios provenientes dos Estudos Feministas (e 
também do campo dos Estudos Negros, dos Estudos Culturais, dos Estudos Gays e Lésbicos) podem se tornar elementos muito importantes para afinar o olhar, estimular inquietações, provocar questões. (LOURO, 2003, p.83)

Segundo a autora, para podermos interferir pedagogicamente e contribuirmos com o combate ao preconceito, não basta sermos apenas sensíveis, é necessário, também, debruçar-nos no conhecimento teórico que possa auxiliar-nos nessa intervenção.

Esse reconhecimento da importância das teorizações, das pesquisas e dos ensaios como elementos importantes para afinar o nosso olhar, também é defendido por Costa (2015, p.18), ao destacar que:

Antes, ainda é urgente desenvolver a formação de professores em sua dimensão teórica e na produção do conhecimento por intermédio da pesquisa. Posto que "A aversão à teoria constitui a fragilidade da práxis", como afirmado por Adorno (1995), com vistas à superação da pseudo ideia de que a práxis docente e os métodos canônicos de ensino, possam ser pensados e admitidos com um fim em si mesmos, como também, suficientes no enfrentamento e na problematização dos limites sociais, impostos historicamente aos professores, como sendo limites humanos.

A formação teórica poderá subsidiar os professores para que tenham sensibilidade e conhecimento adequado para lidar com os limites sociais, impostos historicamente, levando-se em conta que a práxis, por si mesma, desprovida de teoria, se torna frágil e não é capaz de promover a formação adequada para intervir conscientemente no combate ao preconceito na escola.

A formação que se construiu, também, pelo conhecimento teórico e pela pesquisa, possibilitou ao professor de Geografia ter sensibilidade e aptidão para introduzir o tema da homoafetividade em sua turma de EJA, sem afrontar e nem desrespeitar as concepções e representações dos alunos aceca da temática, mesmo porque, muitas de suas concepções e representações preconceituosas acerca da homoafetividade são provenientes de um processo histórico que valoriza determinados grupos de pessoas em detrimento de outros. De acordo com Louro (2003, p.50):

Em nossa sociedade, devido à hegemonia branca, masculina, heterossexual e cristã, têm sido nomeados e nomeadas como diferentes aqueles e aquelas que não compartilham desses atributos. A atribuição da diferença é sempre historicamente contingente $\circlearrowright$ ela é dependente de uma situação e de um momento particulares.

Essa hegemonia influencia nas concepções e representações de nossos alunos acerca da homoafetividade, pois os mesmos, estão inseridos nessa sociedade, onde ainda se supervaloriza os valores difundidos pela etnia branca e pela heterossexualidade.

Deixar de opinar, seja afirmativamente ou negativamente, é muito prejudicial na desconstrução dos tabus que resultam no preconceito. E, para que este não esteja presente e seja manifesto em suas diferentes faces, tanto na escola, quanto na sociedade, é sempre necessário que o professor da EJA e das demais modalidades de ensino, possam abrir espaços de 
diálogo. Não de discussões onde se prevaleça o discurso unilateral, mas sim, dialético, onde ambos interlocutores possam ter suas colocações respeitadas. E, o professor deverá ser sensível para que o discurso unilateral e/ou maniqueísta, não se faça hegemônico nas discussões em sua turma.

\section{Resultados e considerações}

Primeiramente, o professor começou o diálogo de interferência ao sinalizar que, como nenhum grupo havia escolhido apresentar o movimento LGBT, gostaria de ter a oportunidade de saber da turma suas concepções acerca do movimento. Foi dirigida a seguinte pergunta à turma: ñocês já ouviram falar do Movimento LGBT?òMuitos responderam que sim. Depois o professor deu continuidade: r̃Conhecem o seu objetivo e seus ideais de luta?à Muitos, também, responderam que sim. Porém, outros preferiram não comentar. Dando prosseguimento ao diálogo, perguntou se algum aluno já havia frequentado uma parada gay? Poucos disseram que sim e que gostaram de estar ali por se tratar de uma festa parecida com o carnaval e muito alegre. Sinalizaram que muitos frequentadores desse evento não eram pessoas homossexuais, mas estavam ali como simpatizantes e/ou até mesmo, como forma de diversão. Nesse momento, o professor precisou interferir ao afirmar que os movimentos sociais podem e devem estar ligados aos movimentos culturais, como samba, capoeira, funk, teatro e etc., pois, ao se estabelecer o diálogo e a interação com as manifestações artísticas ou culturais, ambos poderão se beneficiar através da troca de experiências. Mesmo porque, as manifestações artísticas costumam usar múltiplas linguagens e atrair, também, um grande público que possa vir a conhecer a causa de um movimento social.

Percebeu-se que no momento em que o diálogo foi aberto à turma e as perguntas sendo formuladas pelo professor, um número maior de aluno passou a demonstrar interesse em falar da temática que, à priori, parecia ser desinteressante e obscura. Isso demonstrara que a falta de apatia em relação ao tema era resultante de um processo histórico-social em que fez-se pensar que questões ligadas à sexualidade e, muito mais ainda, à homoafetividade não fossem dignas e tivessem espaço de diálogo em sala de aula.

Deixar de interferir pedagogicamente, estaria, indiretamente, contribuindo para que o preconceito contra à diversidade de gênero fosse ainda mais difundido em nossa sociedade. Era preciso falar do assunto, discutir e desmistificar os preconceitos. Pois, segundo Crochik, 2015, p.50):

O preconceito é um fenômeno social, que indica a restrição às experiências individuais, as quais são necessárias para a constituição desses indivíduos. Se o problema tem origem social, a educação escolar, que é uma instituição social, não pode por si mesma superar o que não produziu sozinha, mas pode contribuir com a formação de consciências que levem a pensar o que nos torna insensíveis. 
O preconceito não é um fenômeno biológico. Não nasce com o ser humano. É fruto da experiência do indivíduo com a cultura em que se está inserido. Por isso, se o problema tem sua origem na sociedade e a escola está inserida nesta sociedade, caberá também à mesma contribuir com a desconstrução dessas concepções preconceituosas.

As concepções preconceituosas dos alunos acerca da homoafetividade eram provenientes do senso comum, da igreja e de outras esferas que supervalorizam o binarismo homemmulher.

Como havia sido criado um ambiente propício entre professor e alunos para se discutir a temática e se estabelecido acordos para que se respeitassem a opinião de todos, pôde-se falar de questões defendidas pelo movimento LGBT, como: casamento de pessoas do mesmo sexo e adoção de crianças por casais homossexuais.

Um terço da turma declarou não ter nada contra às questões defendidas pelo movimento LGBT, um terço disse estava em dúvida, ainda o outro terço preferia não opinar.

Os alunos que se declararam evangélicos e católicos, mesmo se envolvendo muito pouco no diálogo, reconheceram que o mesmo fazia parte do currículo, negociado entre professor e alunos e era conduzido de forma séria e respeitosa, não pretendendo ser maniqueísta, mas sim, oferecendo oportunidades para que concepções teóricas e científicas acerca do tema, fossem debatidas, conhecidas e confrontadas com questões do senso comum e religioso. O professor pode expor a ideia defendida por Louro (2003, p. 54) de que as identidades de gênero são construídas ao longo da vida, ao dizer:

O que importa aqui considerar é que $\delta$ tanto na dinâmica do gênero como na dinâmica da sexualidade ठ as identidades são sempre construídas, elas não são dadas ou acabadas num determinado momento. Não é possível fixar um momento ठ seja esse o nascimento, a adolescência, ou a maturidade $\succsim$ que possa ser tomado como aquele em que a identidade sexual e/ou a identidade de gênero seja "assentada" ou estabelecida. As identidades estão sempre se constituindo, elas são instáveis e, portanto, passíveis de transformação.

E, muitos (as) alunos (as) da turma, reconheceram em suas falas que as identidades dos seres humanos estão sempre em transformação. Alguns relataram que quando criança, frequentaram a religião dos pais, mas que na fase adulta, decidiram optar por outras religiões e, até mesmo não pertencer a nenhuma denominação religiosa. E, muitos outros, relataram que, com o tempo, os seus gostos e visão de mundo foram se ampliando e se modificando. Isso possibilitou ao professor acrescentar que a nossa identidade de gênero e sexual, também poderá ser transformada com o tempo. Ela sempre estará inacabada.

Muitos foram favoráveis à ideia de que todas as pessoas têm o direito de optar por sua identidade de gênero e que, mesmo aqueles que não aceitam tal escolha, deveria respeitar a escolha do outro. Também, muitos alunos declararam que o movimento LGBT deva continuar 
lutando pelos direitos de sua comunidade e que se trata de um movimento que deva ser estudado nas escolas, assim como qualquer outro movimento social.

Mesmo que exista muito tabu na sociedade acerca da homoafetividade e isso venha se traduzir na manifestação do preconceito na escola, é possível amenizar essa realidade tão estagnadora do processo civilizatório, desde que se perceba que muito ainda se possa fazer para reverter esse quadro.

\section{REFERÊNCIAS}

COSTA, V. A. da. Possibilidades da Formação e da Pesquisa à Educação Inclusiva. In: COSTA, V. A. da. (Org.) Formação e Pesquisa: articulação na educação inclusiva. Niterói: Intertexto, 2015.

CROCHÍK, J. L. Educação Inclusiva, subjetividade, preconceito e direitos humanos: qual sua relação? In: SILVA, A. M. M; COSTA, V. A. da. (orgs.) Educação inclusiva e direitos humanos perspectivas contemporâneas. 1 edição. São Paulo: Cortez, 2015.

LOURO, G. L. Gênero, Sexualidade e Educação Uma perspectiva pós-estruturalista, Petrópolis: Vozes, 2003. 